\title{
NECESSIDADES PSICOSSOCIAIS DO MENOR DE BAIXA RENDA, NA FAIXA ETÁRIA DE 10 A 15 ANOS*
}

\author{
Maria de Fátima Guenes de Oliveira** \\ Estela Meirelles Monteiro**
}

\begin{abstract}
RESUMO - Este estudo visou apreender a problemática psicossocial de menores de 10 a 15 anos, a fim de obter dados que ampliem a capacitação operacional na área de Enfermagem em Saúde Mental Comunitária junto à famllias de baixa renda. Pesquisa do tipo exploratório, utilizando-se o método etnográfico combinado com a entrevista. Os resultados evidenciam a precariedade das condições sócio-econômicas em que vivem, a carência de afeto e a violência física e moral com que são educados, etc... Suas doenças incidem nos males físicos, com pouca referência a problemas atingindo diretamente a saúde mental.
\end{abstract}

\begin{abstract}
This study intended to apprehend the psychosocial problematic of minors between ten to fifteen years of age, to obtain data which enlarge the operational capability in the Nursery of Community Mental Health field within the low-profit family. It was made an exploratory research, utilizing the ethnographic method combined with the interview. The results evidence the social and economic precariousness in which the poor people lives, specially the affective missing, physical and moral violence as they are educated, etc... Their most common diseases are of the physical type, with little reference to problems which may directly attain their mental health.
\end{abstract}

\section{INTRODUÇÃO}

Apesar da saúde ser considerada um direito humano fundamental e um objetivo social, constata-se que atualmente, aindà grande parcela da população brasileira encontra-se desassistida dos serviços de saúde, justamente os indivíduos menos privilegiados socialmente.

Landmann apud CASTRO (1982), afirma ser a saúde da comunidade influenciada diretamente por fatores econômicos e sociais, os quais u trapassam a escassa contribuição que a medicina pode dar. A elevação dos padrões de vida ou a transformação social da população certamente teria maior influência sobre seu estado de saúde do que a obtida por qualquer diretriz dos serviços assistenciais. A horrenda desumanização que resulta da massificação da pobreza é primariamente um problema de distribuição de riqueza e os problemas de saúde são uma conseqüência social.

Enquanto não se processa essa transformação social, cabe ao profissional da nossa área promover a melhoria do nível de saúde do indivíduo, família e comunidade, reconhecendo os fatores físicos, psíqui$\cos$ e sócio-culturais que neles interferem, determinando o nível de sensibilidade à tensão, como o grau de vulnerabilidade à doença física e mental a que estão submetidos.

A família exerce influência marcante no desenvolvimento da personalidade do indivíduo, e o cuidado pela saúde do menor se inicia no núcleo familiar, mesmo antes da concepção. Segundo GONÇAL VES (1983), "mulheres atemorizadas pela fome, pela miséria, privadas de uma vida sexual gratificante (negada àqueles que vivem de forma precária em seu cotidiano), geram a cada momento crianças que compartilham, no interior silencioso desses úteros, carência de alimentação material e afetiva, crianças que submetidas à brutalidade do cotidiano vivido à sombra penosa do salario mínimo (no caso das classes populares), serão, por certo, muito mais vulneráveis às pressões de vida material e suas repercussões sobre a vida simbólica".

A integridade espiritual e física do menor deve ser salvaguardada, visando a obtenção de um melhor nível de saúde a médio e longo prazos. Conforme os dados fornecidos pelo IPLAN/IPEA ${ }^{2}$, em 1985, o Brasil é caracterizado como um país demograficamente muito jovem, pois cerca de $45 \%$ da população brasileira é constituída por menores de 18 anos de idade, representando aproximadamente 60 milhões de pessoas. Daí a importância de se trabalhar com integrantes desse grupo tão numeroso quanto suscetível e vulnerável às influências do ambiente em que estão inseridos. Para CAPL AN ${ }^{3}$ toda pessoa necessita de suprimentos físicos, psicossociais e sócio culturais contínuos e compatíveis com seu estágio atual de crescimento e desenvolvimento. Os suprimentos psicossociais são a estimulação ao desenvolvimento cognitivo e afetivo através da interação pessoal com família e colegas para satisfação de necessidades interpessoais de amor, afeto, limitações, controle e participação. Segundo $\mathrm{MINZONI}{ }^{13}$, o indivíduo considerado como pessoa e como ser social recebe e exerce influências sobre o ambiente em sua vida diária, na comunidade. A negligência, ausência ou inadequação no atendimento de necessidades psicossociais do menor de baixa renda, por parte dos pais, responsáveis ou educadores, que desconhecem sua importancia geram graves desajustamentos. $\mathrm{O}$ número cada vez mais elevado de margi-

\footnotetext{
* Trabalho classificado em $2^{\circ}$ lugar-Prêmio Edith Magalhäes Fraenkel-40 CBEn-Belém.

** Enfermeiras de Pernambuco.
} 
nalidade, criminalidade e violência de pessoas que em sua maioria são da classe pobre, reclama uma atuação urgente das autoridades competentes nessas comunidades.

A Enfermagem, comprometida com a mudança social, em sua função educativa e preventiva deverá ser elemento de promoção de saúde mental comunitária. A doença mental, desajustamento, ou distúrbio emocional que um indivíduo seja portador, atinge não somente a ele e sua família, mas de algum modo também a comunidade onde ele vive.

Com base na experiência vivenciada na Comunidade Santa Luzia, no Bairro da Torre, em que se teve oportunidade de atuar junto aos menores da Unidade Produtiva e também com outros jovens daquela comunidade, os quais se apresentaram receptivos, curiosos e desinformados acerca de assuntos elementares relativos à higiene corporal, desenvolvimento físico e emocional, educação sexual, prevenção de vícios, preparação para o convívio social, etc...., sentiu-se o interesse de pesquisar sobre as necessidades psicossociais do menor de baixa renda na faixa etária dos 10 aos 15 anos, de uma outra comunidade marcada ainda mais duramente pela pobreza.

Esse estudo foi desenvolvido no Loteamento Jardim Justiça e Paz, comumente denominado "TURURU”, localizado no Bairro do Janga, Município de Paulista - PE, que aglomera cerca de 4.000 moradores em precárias condições de vida. É uma realidade dessa comunidade, a precocidade com que as crianças são entregues à própria sorte, pois em torno dos 7 anos de idade já são encarregadas dos afazeres domésticos, do cuidado dos irmãos menores, da venda de frutas ou verduras, e do transporte das "trouxas de roupa". As precárias condições assistenciais de saúde somadas às precárias condições de vida em que se encontram os menores das famílias de baixa renda, afetam sua saúde física e mental, prejudicando assim seu desenvolvimento.

Essa pesquisa visou apreender a problemática psicossocial de menores de 10 a 15 anos, a fim de ampliar a capacitação operacional na área de Enfermagem em Saúde Mental Comunitária, junto a famílias de baixa renda identificando as necessidades psicossocias referidas por grupos infanto-juvenis dessa comunidade.

Maltratar a criança é um problema complexo, determinado por causas múltiplas, que parece estar crescendo de magnitude. Conforme estudo de DAVIDOFF (1985), cientistas comportamentais traçaram o perfil do pai ou mãe que maltrata. Eles acreditam que os estresses sociais contribuem de modo significante para os maus tratos às crianças. A violência é especialmente provável em famílias tensas, extremamente pobres, onde o homem está empregado apenas parte do tempo ou desempregado.

Grande parte do comportamento humano parece ser dirigido à satisfação de motivos sociais, aqueles cumprimento depende do contato com outros seres humanos. Esses motivos surgem para satisfazer as necessidades de sentir-se amado, aceito, aprovado e estimado. Estudiosos como Adler, Horney, Sullivan, todos citados por DAVIDOFF (1985) enfatizaram a importância das influências sociais sobre a personalidade, destacando o contexto social do desenvolvimento.

A pesquisa aqui apresentada foi baseada na Teoria do Desenvolvimento de ERIKSON (1976), segun- do a qual as personalidades se formam à proporção que as pessoas progridem por estágios psicossociais através da vida. A cada novo estágio há um conflito a enfrentar e a resolver; há uma solução positiva e negativa para cada dilema. Os conflitos estão todos presentes no nascimento mas se tornam predominantes em pontos específicos do ciclo da vida. As soluções positivas resultam em saúde mental, ao passo que as negativas conduzem a desajustamento. A solução de qualquer conflito depende, em parte, do sucesso com que os dilemas anteriores foram tratados. Contudo, a saúde mental não fica estabelecida de uma vez para sempre. Experiências posteriores felizes e infelizes podem contrariar as anteriores.

Durante o primeiro ano de vida (paralelamente à fase oral de Freud), os bebês enfrentam o conflito entre CONFIANÇA x DESCONFIANÇA. No segundo ano de vida (fase anal de Freud), as crianças enfrentam um segundo desafio: AUTONOMIA $x$ VERGONHA e DÚVIDA. As crianças com 3 ou 4 anos (fase fálica de Freud), enfrentam um novo conflito: INICIAÇÃO x CULPA. A criança de 6 a 11 anos de idade entra num novo mundo - a escola - com suas próprias metas, limites, fracassos e realizações. Surge o quarto maior desafio: DILIGÊNCIA x INFERIORIDADE. Quando as crianças se sentem menos adequadas do que seus pares em realizações, habilidades e capacidades, desenvolvem um senso de inferioridade. As de sucesso emergem com um sentimento de competência e prazer no trabalho, um senso de diligência.

$\mathrm{Na}$ adolescência (quando começa a fase genital de Freud), ocorre uma crise de identidade. Se a crise não for resolvida, os jovens sentirão confusão de papéis. $\mathrm{O}$ adolescente precisa integrar diversas auto imagens como jovem, amigo, estudante, líder, seguidor, trabalhador, mulher ou homem - em uma única imagem e escolher uma carreira e estilo de vida. Conseguindo confiança básica, autonomia, iniciativa e diligência, os jovens poderão conseguir mais facilmente uma identidade. Se esta crise for superada, os indivíduos emergirão com um senso de quem são e para que servem. Erikson acredita que a busca de identidade explica muitos padrões típicos do comportamento do adolescente.

A adolescência é uma época de vida em que o corpo muda radicalmente suas proporções, quando a puberdade genital inunda o corpo e a imaginação com todas as espécies de impulsos, quando a intimidade com o outro sexo se aproxima e, ocasionalmente, é forçada ao jovem e quando o futuro imediato confronta uma pessoa com muitas possibilidade e escolhas conflitantes.

As pessoas que não desenvolveram o senso de identidade pessoal encontram dificuldades em estabelecer relacionamentos íntimos; algumas vezes elas se isolam. De outras, formam laços frágeis que se rompem na primeira dificuldade. Durante os anos adultos, de meia idade, e velhice, os conflitos continuam.

Com esse estudo pretendeu-se investigar numa comunidade específica marcada por carências sócioeconômicas diversas, as necessidades psicossociais dos menores que ali vivem. Observe-se aqui que os conflitos básicos deles não foram abordados de forma direta, e sim atentando-se para aspectos que contribuiriam ou não para a resolução adequada dos mesmos. 


\section{METODOLOGIA}

\section{População e Amostra}

Concentrou-se a faixa etária em 10 a 15 anos, na tentativa de se obter dados mais consubstanciais para o estudo na comunidade do "TURURU", supondo-se que as crianças com idade inferior a 10 anos não apresentariam amadurecimento cognitivo suficiente para compreender certos tópicos da pesquisa.

Não menosprezando as características de integralidade, equiprobabilidade, inequivocidade e insubstituibilidade, a amostra das 550 unidades componentes do "TURURU" foi escolhida sem qualquer tendenciosidade/parcialidade, eliminando-se o fator pessoal. Além disso, os componentes da amostra foram completamente independentes entre sí, mantendo-se as mesmas condições para todos os componentes amostrais. A amostra foi aleatória simples, levando-se em conta a hipótese de que a percentagem de meninos entre 10 e 15 anos era idêntica a de meninas daquela mesma faixa etária. Aplicou-se o cálculo segundo um nível de significância de $95 \%, p=q$ e uma fidedignida de de $10 \%$, comportando um quantitativo de 150 unidades, obedecendo-se os seguintes critérios:

- lotes numerados e sorteados;

- em cada unidade amostral foi feita listagem dos integrantes situados na faixa etária de 10 a 15 anos, preenchendo-se uma folha geral de identificação;

- dos integrantes listados em cada unidade amostral um foi sorteado, registrado no formulário de caracterização da amostra, e em seguida entrevistado;

- para suprir as unidades amostrais desocupadas, ou que se recusaram a participar da pesquisa ou que não possuiam menor na faixa etária estabelecida, considerou-se nova unidade amostral, substituta da cancelada, a de número imediatamente superior ainda não sorteada;

- as entrevistas foram numeradas de 000 a 150.

\section{Método e Instrumento}

A pesquisa foi do tipo exploratório pelo fato de se destinar a buscar informações e em vista da insuficiência de dados prévios que permitissem a elaboração de uma hipótese sobre o problema em questão. Dada a natureza da investigação cientifica, utilizou-se o Método Etnográfico, combinado com entrevista que permitiu a coleta de dados mais específicos. Para isso foi usado um roteiro de entrevista constituído dos tópicos a seguir relacionados, perfazendo um total de 69 itens.

- ESCOL ARIDADE (5 itens)

- DINÂMICA FAMILIAR (7 itens)

- SAÚDE/ALIMENTAÇÃO/HIGIENE (7 itens)

- OCUPAÇÃO E REGIME DE TRABALHO (10 itens)

- CONSCIÊNCIA GRUPAL (9 itens)

- LAZER (10 itens)

- SEXUALIDADE/VÍCIOS (13 itens)

- CONSCIÊNCIA DE SI (7 itens)

\section{Testagem do Instrumento}

Elaborou-se um questionário como instrumento de coleta de dados. Após foi testado com menores na faixa etária de 10 a 15 anos, residentes na Comunidade Planeta dos Macacos, por apresentar semelhança com a comunidade do "TURURU" nos aspectos sócioeconômico-culturais, concluindo-se que tal instrumento iria onerar demasiadamente o custo da pesquisa. Sendo assim, optou-se pela realização de um roteiro de entrevista que contivesse os mesmos tópicos já testados no questionário.

\section{Técnica de Coleta de Dados}

Uma das autoras do presente trabalho estabeleceu os contatos iniciais com as lideranças da comunidade, ense jando a realização de atividades práticas exigidas por outras disciplinas da Especialização em Enfermagem em Saúde Mental Comunitária.

Atendendo a solicitação da diretora da Escola Estadual São José do "TURURU", as autoras realizaram um curso para as professoras daquela instituição, sobre as fases do desenvolvimento psicossexual e psicossocial da criança.

$\mathrm{Na}$ preocupação de se manter um contato contínuo com a comunidade, participava-se das reuniões da Associação de Moradores, freqüentava-se o Posto de Saúde alí existente, com a finalidade de, através da integração no dia-à-dia e realidade dos moradores do "TURURU", tornar possível uma observação etnográfica que consistiu na descrição da comunidade a partir do ponto de vista de seus moradores. O conhecimento de suas crenças, valores, linguagem, etc... viabilizou a interpretação dos comportamentos considerando esses aspectos, segundo o pensamento de GE$\operatorname{ERTZ}^{9}$ (1981).

\section{Procedimento para Análise dos Dados}

Os dados foram analisados quantitativa e qualitativamente, visando identificar as necessidades psicossociais que estão af etadas nos menores entrevistados e relacionar a problemática extraída da coleta de dados com o local de moradia dos menores e o contexto sócieconômico-político-cultural em que vivem.

\section{Tratamento Estatístico dos Dados}

Os dados foram tabulados manualmente, construindo-se tabelas simples e cruzadas, além de quadros, sendo utilizados valores absolutos e percentuais. Nas tabelas que contêm respostas múltiplas, o percentual foi calculado em função do total de entrevistados.

\section{Critérios para Caracterização das Respostas}

A maioria das respostas permaneceu discriminada individualmente a fim de não se perder detalhes que enriqueceriam o estudo. Algumas respostas foram agrupadas mediante a semelhança existente entre elas, tendo-se o cuidado de preservar as idérias principais.

\section{ANÁLISE E INTERPRETAÇÃO DOS DADOS}

Os dados serão apresentados obedecendo-se a seqüência dos tópicos que constituem o roteiro de entrevista utilizado para a coleta de dados. A primeira parte 
refere-se a análise dos dados de caracterização da amostra, as demais relacionam-se com os tópicos referidos anteriormente.

\section{Caracterização da População}

Os dados coletados nessa pesquisa indicam que a amostra estudada caracterizou-se por um total de 72 meninos (48\%) e 78 meninas $(52 \%)$, na faixa etária de 10 a 15 anos, dos quais $145(96,7 \%)$ são pernambucanos, apenas $4(2,6 \%)$ são paraibanos e $1(0.7 \%)$ é procedente de São Paulo.

Quanto à religião, constatou-se que 88 (58,7\%) dos entrevistados são Catóticos (nem todos praticantes), 19 (12,7\%) são Evangélicos, 2-1 (3\%) freqüentam a Casa da Bênção, $1(0,7 \%)$ Espírita Kardecista e 40 $(26,6 \%)$ declaram não ter religião. Com relação a este último aspecto, de acordo com MASLOW (1979), as pessoas podem adotar religiōes e filosofias para organizar suas vidas e ter uma sensação de segurança. Confrontando essa assertiva com os resultados obtidos, pode-se asseverar que o elevado índice de menores sem religião, somado ao número daqueles que apesar de se dizerem católicos, reconhecem não serem praticantes, por certo representa um fator agravante que se acresce às suas precárias condições de vida.

A concentração do tempo de residência da família na comunidade apresentou-se maior entre 1 a 5 anos $(32,7 \%)$ e mais de 10 anos $(29,3 \%)$. A freqüência e percentual dos entrevistados por sexo e cada idade que compõe a faixa etária estudada, que apresentou o total de maior concentração foi o da idade de 10 a 12 anos.

Os tipos de moradia variavam desde alvenaria (62\%), até as de paredes e teto de palha de coqueiro $(1,3 \%)$. As residências de 4 cômodo (quarto-sala-cozinha-banheiro) ou 2 (quartos-sala-cozinha), foram as que apresentaram percentual mais elevado $(39,3 \%)$, seguidas das de 1 único vão $(23,3 \%)$. Com isso comprovou-se a inadequação das condições de co-habita- ção uma vez que diante de uma média de 6,5 pessoas por residência, o número de cômodos de que dispõem é insuficiente, pois dificulta a privacidade e se constitui um fator de estress. A inexistência de fossa em $64 \%$ das residências e de água encanada em $100 \%$ delas evidencia a dificuldade dos que residem naquela localidade, no atendimento de suas necessidades higiênico/sanitárias mais elementares. Por não existir serviço de coleta de lixo a comunidade, seus moradores solucionam esta deficiência jogando o lixo na lagoa, na mata, em terrenos baldios, etc... Ruas com água empoçada, falta de saneamento básico e falta de água tratada propiciam a incidência de várias doenças que serão mais bem explicitadas no tópico saúde.

\section{Escolaridade}

Dos entrevistados $4,7 \%$ nunca estudou e $6,7 \%$ não estudam no momento, somando um total de $11,4 \%$. Dentre os motivos explicitados pelos que nun . ca estudaram apresentam-se: falta de dinheiro para retirar o registro civil; a mãe não tem tempo para matriculá-los; nunca quiseram estudar e não gostam de estudar por achar cansativo. Já os motivos apontados pelos que não estudam foram: precisar trabalhar, não querer estudar, não gostar de estudar, ter dificuldade de aprendizagem, precisar cuidar da filha de 6 meses e precisar cuidar da irmã pequena porque a genitora trabalha. Vê-se assim que algumas necessidades materiais impedem o acesso desses menores à escola, uma vez que a existência de várias instituições estaduais e municipais de ensino do $1^{\circ}$ e $2^{\circ}$ graus na comunidade não suscita o interesse.

O nível de escolaridade dos entrevistados em função da faixa etária apresenta-se bastante distorcido, pois os percentuais mais altos concentram-se na $2^{\mathrm{a}} \mathrm{e}$ 3 séries do $1^{\circ}$ grau, quando os da faixa etária de 13 a 15 anos deveriam estar concluindo o 1 - grau. Apenas 1 $(0,6 \%)$ está na 8 a série (Tabela 1$)$.

Tabela 1

DISTRIBUIÇÃ O DA ESCOLARIDADE, SEGUNDO A IDADE DOS ENTREVISTADOS

\begin{tabular}{|c|c|c|c|c|c|c|c|c|c|}
\hline $\begin{array}{l}\text { ESCOL ARIDADE } \\
\text { IDADE } \\
\text { (ANOS) }\end{array}$ & $\begin{array}{l}\text { NUNCA } \\
\text { ESTUDOU }\end{array}$ & $1 \underline{a}$ & $2^{\mathrm{a}}$ & $3^{\mathrm{a}}$ & $4^{\mathrm{a}}$ & 5 & $6^{a}$ & $7^{\mathbf{a}}$ & $8^{\mathrm{a}}$ \\
\hline $\begin{array}{l}10-12(84) \\
13-15(66)\end{array}$ & $\begin{array}{l}2 \\
5\end{array}$ & $\begin{array}{r}11 \\
7\end{array}$ & $\begin{array}{r}35 \\
5\end{array}$ & $\begin{array}{l}20 \\
11\end{array}$ & $\begin{array}{r}9 \\
16\end{array}$ & $\begin{array}{l}4 \\
9\end{array}$ & $\begin{array}{l}3 \\
8\end{array}$ & 4 & 1 \\
\hline TOTAL & 7 & 18 & 40 & 31 & 25 & 13 & 11 & 4 & 1 \\
\hline$\%$ & 4,7 & 12,0 & 26,7 & 20,7 & 16,7 & 8,6 & 7,3 & 2,7 & 0,6 \\
\hline
\end{tabular}

Para ERIKSON (1976) a criança na idade escolar enfrenta o desafio diligência $\mathrm{x}$ inferioridade, e a criança que se sente inadequada em realizações, habilidades e capacidades desenvolve um senso de inferioridade. Sendo assim, pode-se afirmar que o atraso na escola dos menores entrevistados no "TURURU" se soma as experiências anteriores infelizes, que provavelmente vivenciaram em seu cotidiano, dificultando desse modo sua progressão nos estágios psicossociais através da vida.

\section{Dinâmica Familiar}

Constatou-se que apenas 68 dos entrevistados residem com a família nuclear; 25 só com a mãe e os 
irmãos, e os 57 restantes têm o grupo familiar constituído pela mãe, sobrinhos, irmãos, avós, tios, primos, cunhados, madrastas, padrastos, namorado, estruturando-se famílias com as mais diversificadas combinaçōes.

Conforme citação de Parsons, referido por FER $\mathrm{NANDES}^{8}$, as relações humanas vivenciadas com a família nuclear (pai-mãe-irmãos) projetam-se nos grupos maiores do contexto social, a comunidade, a sociedade civil. Pode prever-se as dificuldades que certamente enfrentarão os menores que não usufruem do convívio dos pais. Nesse ponto cabe enfatizar que o processo de identificação deles pode estar prejudicado. Segundo ERIK SON ${ }^{7}$, na adolescência os jovens passam por uma crise de identidade. Caso a crise não se ja resolvida, eles sentirão confusão de papéis. $\mathrm{O}$ adolescente precisa integrar várias auto-imagens em uma única imagem e escolher uma carreira e estilo de vida. $\mathrm{Na}$ realidade dos jovens do "TURURU”, a presença da mãe é a permanente segurança que lhes resta. Com quem se identificar? Como futuramente compor sua própria família? e os papéis? e as atribuições e tarefas? Dos entrevistados $18(12 \%)$ têm a responsabilidade de cuidar da casa sozinhos e $32(21,3 \%)$ dividem esta ta refa com outros.

Respondendo sobre o que acontece quando fazem alguma coisa errada e os seus pais ou responsáveis não gostam, $60(40 \%)$ dos menores afirmaram que apanham; $52(34,6 \%)$ ouvem reclamação; $13(8,6 \%)$ ouvem reclamação e apanham, e somente $5(3,3 \%)$ recebem conselho. Os objetos com os quais os pais ou responsáveis batem nos menores variam desde o chinelo, cinturão, mão, cipó, correia (borracha), fio de eletricidade, palmatória, até vara. Uma das entrevistadas apresentava várias cicatrizes no corpo, que segundo ela foram provocadas por sua avó, que embriagada jogou-a diversas vezes no arame farpado.

Observando-se essa realidade de sanções e castigos infligidos nos menores do "TURURU", confirmase o estudo dos cientistas comportamentais citados por DAVIDOFF (1987), no que se refere ao perfil do pai ou mãe que maltrata. Os estresses sociais e a tensão provocada pela pobreza contribuem para que esses pais quando com raiva cometam atos que ferem, além dos antecedentes que lhes ensinaram o uso da agressão como uma das táticas principais na criação dos filhos. Com isso pode se supor que esse doloroso aprendizado será passado para os filhos destes que hoje são assim maltratados.

Adicione-se à evidência da agressão física e moral, a taxativa resposta negativa de 51 (34\%), e a incerteza de $7(4,7 \%)$ dos menores no item onde se indagava se ELES SENTIAM-SE AMADOS POR ALGUÉM. Muitos deles apresentaram lágrimas nos olhos; dois chegaram a chorar, sendo necessário parar a entrevista e aguardar que se recompusessem.

Conforme Parsons, citado por FERNANDES (1979), todo ser humano para ser bem sucedido carece de amor, afeto, segurança que abranja todas as suas necessidades, fazendo com que aprenda a amar, a ser futuro pai ou mãe, preservando a hominalidade da espécie humana. $\mathrm{O}$ que pensar diante do que foi observado e detectado desde os primeiros contatos junto aos menores da comunidade, e comprovado na pesquisa no que se refere a carência de afeto e precocidade com que são eles entregues à própria sorte? Para JASPER "o amor é o primeiro estímulo para o desenvolvimento emocional/social'. Que alternativas têm aqueles menores?

\section{Saúde - Alimentação}

A grande maioria dos menores entrevistados declarou alimentar-se três vezes ao dia, com alimentação comum no cardápio do nordestino (café - pão - leite cuscuz - feijão - macarrão - peixe - galinha - carne bovina, etc...) . As autoras desse trabalho questionam essa resposta, por conta da realidade que observavam nas residências sorteadas. Apenas 2 (dois) entrevistados confessaram alimentar-se duas vezes ao dia, e 1 (um) em dias alternados.

Quando alguma pessoa da família adoece, apenas $44(29,3 \%)$ referiram que procuram o Posto de Saúde da Comunidade, o que representa um percentual reduzido para uma comunidade de baixa renda, onde há muita dificuldade de transporte.

As principais doenças dos jovens da comunidade variavam desde os sintomas: febre $(28,6 \%)$, dor de cabeça (22\%); às doenças: sarampo $(20,6 \%)$, catapora $(14 \%)$, verminose $(14 \%)$, problemas de pele "creca pereba - sarna" (10\%), "cansaço" (dispnéia - asma) $(6,6 \%)$, até "nervosismo" (3\%) e "problema de cabeça" $(0,6 \%)$. Com isto verifica-se que ali prevalece a queixa de doenças físicas atingindo só o corpo. Passa desapercebida a probabilidade de que as precárias condições de vida, mais o estress em que vivem, possam desencadear um ciclo onde o psiquismo af etado atinge o corpo e vice-versa, se instalando as doenças psicossomáticas. No "TURURU" a saúde mental é desconhecida, o que pode ser explicado pelas prementes necessidades humanas básicas que ainda não estão sendo devidamente atendidas.

\section{Ocupação e Regime de Trabalho}

Dos 150 entrevistados 109 não exercem atividade remunerada, 24\% trabalham, sendo que 3 (três) desses não recebem salário, pois ajudam aos pais na mercearia ou lavagem de roupa. O tipo de ocupação que desenvolvem, de certo modo é a repetição encontrada nas profissões dos pais ou responsáveis.

\section{CONSCIÊNCIA GRUPAL}

Do total de entrevistados apenas $6,6 \%$ participam de algum grupo na comunidade. Vale ressaltar que $30 \%$ afirmaram não ter grupo na comunidade, $11,3 \%$ declararam existir grupo na comunidade e $5,3 \%$ não sabiam se havia grupo no "TURURU". Verifica-se o quanto a interação afetiva desses menores no grupo familiar pode ainda não lhes of erecer a segurança necessária que lhes possibilite interação no contexto social mais amplo que é a comunidade, uma vez que mesmo com a opção de 10 diferentes grupos, a participação comunitária desses menores é pequena.

A atuação dos líderes da comunidade é razoavelmente pecebida, muito embora tenham sido citados por 45 menores que sabem o que eles são na comunidade, enquanto 6 denominaram o presidente de prefeito e 8 de "dono" da comunidade. Os demais não sabem o que eles são na comunidade.

Em resposta ao item relativo aos problemas da 
comunidade, a grande maioria $(67,3 \%)$ referiu o que falta ali, caracterizando fielmente as dificuldades materiais que vivenciam. Alguns $(5,3 \%)$ referiram o fato de pessoas serem encontradas mortas jogadas na mata que circunda a comunidade. Apenas um menino de 12 anos, citou estar faltando um "psique..." (não soube pronunciar), explicando que se refere à figura de determinada novela apresentada na televisão (psicanalista da novela "Mandala") que iria compreender seus problemas, para assim ajudá-los.

A grande maioria gosta de morar na comunidade. Dos que declararam não gostar de morar na comunidade, referiram ser porque se "pega bicho de pé, pulga e doenças", outros citaram "as pessoas mortas que são jogadas na mata". Vale ressaltar ser esta a segunda vez que tal fato foi citado em resposta a diferentes itens.

\section{Lazer}

Os dados obtidos nos vários itens que compuseram este tópico, evidenciaram um pouco das precárias condições sócio-econômicas em que vivem os residentes do "TURURU”.

Em resposta ao item "qual o divertimento, que se pudessem escolhar, prefeririam", foram citados divertimentos cumuns quais sejam: ir a um Parque de Diversões, "andar" de Bicicleta, passear no Parque 13 de Maio, brincar com brinquedos, carro, boneca. Também foram citadas diversões sofisticadas como surfar, andar de lancha e tomar banho de piscina.

Os divertimentos existentes na comunidade não of erecem muitas opções para os menores; $34,6 \%$ dos entrevistados afirmaram não haver ali nenhum divertimento. Desse modo dificulta-se o acesso deles às atividades lúdicas necessárias ao seu desenvolvimento emocional e social.

Brincar de academia, pular corda, se esconder, pega, bola de gude, jogar bola, pião, brincadeiras de roda (atirei o pau no gato), na areia, com carro e boneca, foi o modo como se divertem $52 \%$ deles. Referiram dançar na "Gandaia"; assistir televisão e ouvir rádio, e conversar, rir e passear. Apesar das poucas opções materiais de lazer, os menores do "TURURU" dispõem de batante espaço físico, ar puro e contato com a natureza, com que podem mais facilmente desenvolver a criatividade.

O programa de telvisão apontado com o favorito foi o "Show da XUXA". Questiona-se o nível de expectativa, fantasia e frustração gerado pela visão de uma realidade completamente diferente daquela que vivenciam em seu cotidiano.

Dos menores, $88 \%$ declararam preferir se divertir com outras pessoas. Já $11,4 \%$ preferem divertir-se sozinhos. Um participante enfatizou que não se diverte.

Razões de preferir divertir-se com outros:

- há mais diversão, há mais divertimento;

- sente-se mais alegre;

- não gosta de estar sozinho ("so, sente um vazio dentro de si");

- só, não tem lógica, com outros se faz um grupo.

Razões de preferir divertir-se sozinho:
- gosta de divertir-se so;

- pessoas são chatas.

Observe-se que enquanto um dos entrevistados viabilizou a possibilidade de interação grupal, denunciando um aspecto sadio do ponto de vista da saúde mental, outro declarou taxativamente que "pessoas são chatas".

\section{Sexualidade/Vícios}

Para ERIKSON (1976) a adolescência é uma época da vida em que o corpo muda radicalmente suas proporções. A puberdade genital inunda o corpo e a imaginação com todas as espécies de impulsos. A intimidade com o outro sexo se aproxima.

As respostas aos itens sobre sexualidade foram dadas com constrangimento por parte dos entrevistados, e em alguns casos percebia-se o constrangimento de seus familiares. Apenas 19,3\% af irmaram já ter recebido orientação sexual. Uma menina de 11 anos comentou que aos 7 anos seu tio tentou estruprá-la na presença dos irmãos menores que choravam. Outro menor referiu: "minha mãe não quer que eu saiba". Atente-se para o elevado índice de menores que declararam não ter recebido orientação sexual $-80,7 \%$. Desses, $22,3 \%$ não querem recebê-la de ninguém, e um entrevistado de pessoa que não o conhecesse.

Questionados sobre o local onde dormem, 23,3\% declararam que toda família dorme no mesmo vão, em camas separadas; $16,6 \%$ junto com os irmãos ou primos, na mesma cama; $26 \%$ só numa cama, dividindo o quarto com os irmãos; $20 \%$ só no quarto; $6 \%$ só, na sala; $4 \%$ dividindo a cama com irmão de sexo diferente; $2 \%$ na mesma cama com a mãe ( 1 afirmou que os pais dormem separados); um só, no banco da sala; outro só, na cozinha e uma terceira com o marido. Esses dados reforçam a afirmativa de que esses menores não têm privacidade e certamente o conhecimento deles sobre sexualidade esteja sendo passado de forma distorcida.

Quando o assunto sobre drogas foi mencionado, os entrevistados falaram com resistência. Alguns comentaram: "eu nunca usei não"; "não sei o que é, mas sei que tem maconheiro"; "não conheço, ouvi falar"; "só conheço de nome". Um entrevistado declarou conhecer maconha e comentou: “AIDS, né?" 33,4\% afirmaram não conhecer, nem ter ouvido falar de droga.

Muitos estudiosos do comportamento humano, e entre eles Sullivan, citado por DAVIDOFF ${ }^{5}$ enfati zam que o comportamento do indivíduo é moldado pelas interações com os pais ou responsáveis principalmente na infância. Embora se ja considerável o número de pais ou responsáveis pelos menores entevistados no "TURURU", que fazem uso de bebida alcólica $(60,6 \%)$ e de fumo $(63,3 \%)$, constatou-se que $78,7 \%$ menores não bebem, e $96,7 \%$ não fumam. Esses dados são promissores para a saúde desses menores. No entanto, não deve ser esquecida a possibilidade de que a situação pode ser modificada quando eles conseguirem, pelo trabalho remunerado, o dinheiro que viabilize a manutenção desses vícios.

\section{Consciência de Sí}

Para MASLOW ${ }^{12}$, após as necessidades fisiolo- 
gicas serem atendidas, surgem as necessidades da pessoa sentir-se protegida, livre de perigo e garantida. Os menores entrevistados não têm as necessidades fisiológicas devidamente atendidas e nem tampouco sentem-se protegidas, pois $28,6 \%$ deles declararam que "apanhar" e "ser maltratado" é o que lhes faz sofrer mais. Este e outros dados evidenciam a violência que se manifesta no meio familiar e social em que vivem. As coisas que alegram esses menores são simples. Brincar, divertir-se, foi a mais citada $(39,3 \%)$; passear $(22,6 \%)$ e namorar $(12 \%)$.

Em resposta ao item: "cite 3 coisas que gostaria de ter agora", a grande maioria mencionou coisas materiais (bicicleta - brinquedo - casa bonita - móveis carro - roupa - dinheiro, etc.). Sendo que bicicleta foi o mais citado. Os demais mencionaram coisas que suprissem sua carência af etiva e emocional, como pode ser visto na relação abaixo:

- Ter a família reunida.

- Te o pai junto.

- Ter o carinho do pai.

- Ter a mãe que faleceu há quatro meses.

- Ter o pai e o tio que faleceram.

- Que a mãe deixasse de beber.

- Ter um irmão (é filho único).

- Ter mais liberdade ("são muito presos").

- Estudar noutra escola.

- Aprender a ler.

- Não abandonar os estudos.

- Ter saúde - confiança - felicidade.

- Ter namorado(a).

- Morar em lugar melhor.

- Ser grande (adulto).

\section{CONCLUSÕES}

No estudo desenvolvido junto aos menores na Comunidade Jardim Justiça e Paz - "TURURU”, três aspectos positivos foram encontrados: a receptividade que demonstraram para com este trabalho, evidenciando que o processo de socialização deles não se encontra prejudicado; a sensibilidade, a solidariedade humana e razoável criticidade que alguns demonstraram, apesar da carência de condições básicas vitais em que vivem, e o contato constante com a natureza, fato que é facilitado pelas condições físicas e geográficas que ali se apresentam.

Os resultados evidenciam a precariedade das condições sócio-econômicas a que estão submetidos. $\mathrm{Re}$ sidências em precário estado de conservação e com insuficiência de cômodos, dificultando a privacidade; a falta de água encanada; de coleta de lixo; de infra-estrutura, de opções para o lazer; de serviços assistenciais de saúde permanentes, o que torna-se mais grave pela inexistência de transporte; de meios de se qualificarem profissionalmente; de mobilização: integração e mobilização comunitária; de orientação sexual e de orientação sobre drogas. Tudo isso somado às dificuldades distintas e particulares a cada um dos entrevistados como a confusa estrutura familiar em que visivelmente se percebia a falta da figura paterna. Suprindo essa lacuna encontra-se a figura da mãe como o único esteio e segurança que lhes resta. É gritante a carência de condições materiais daqueles menores.

A carência de afeto e a precocidade com que as- sumem atividades remuneradas ou responsabilidade com a casa e o cuidado com os irmãos menores; a violência física e moral com que são "educados", somados a falta de religiosidade da maioria dos entrevistados são dados que agravam a problemática psicossocial que vivenciam no seu cotidiano. A defasagem detectada na escolaridade deles é outro dado que preocupa. $\mathrm{O}$ insucesso na escola pode ser decisivo para o acúmulo de fatores negativos que os sobrecarregam e que poderão dificultar o seu acesso a um padrão de vida mais saudável e promissor. Como desenvolverão seu potencial sem auto-compreensão e um estilo de vida satisfatório? Com os insucessos constantes, que identidade conseguirão, se à crise natural da adolescência serão acrescentadas as precárias condições materiais, emocionais e afetivas em que se desenvolvem?

Pelas adversas condições de atendimento de suas necessidades humanas mais elementares, que geram privações psicossociais, pode-se apontar a vulnerabilidade deles à desordem mental. No momento, as doenças incidem nos males físicos, com pouca referência à problemas que afetem a saúde mental. Entretanto, a negligência, a ausência ou a inadequação no atendimento dessas necessidades psicossociais são potenciais de surgimento de graves desajustamentos.

\section{REFERÊNCIAS BIBLIOGRÁFICAS}

1 BORBA, Maria Orleide et alii. Levantamento sócio-econômico e incidência das doenças parasitárias na comunidade de "Tururu". Boletim trimestral da clínica de doenças, infectuosas e parasitárias. Depto de Medicina Tropical, UFPE, Recife, 3(1): 25-47 out/dez, 1984.

2 CALSING, Eliseu Francisco et alii. O menor e a probreza. Brasília. IPLAN/IPEA - UNICEF - SUDENE, 1986 $154 \mathrm{p}$.

3 CAPLAN, Gerald. Um programa de prevenção primária. In: - Princípios de psiquiatria preventiva. Rio de Janeiro, Zahar, 1980. Cap. 3.p.70-103.

4 CASTRO, Ieda Barreiro e. O papel social do enfermeiro: realidade e perspectiva de mudança. IN: - CONGRESSO BRASILEIRO DE ENFERMAGEM, 34, Porto Alegre, Anais ... Porto Alegre, ABEN, 1982, p. 33-52.

5 DAVIDOFF, Linda. Introdução a psicologia. 3. ed. São Paulo, McGraw Hill do Brasil, 1985, 732 p.

6 EDMUNDO, Lygia Pereira. Instituição: escola de marginalidade. São Paulo, Cortez, 1987, 141 p.

7 ERIKSON, Erik H. Infância e sociedade. 2. ed. Rio de Janeiro, Zahar, 1976 p. 226-253.

8 FERNANDES, C.A.F. Aspectos emocionais da criança. Revista Brasileira de Enfermagem. DF, 32: 251-4, 1979.

9 GEERTZ, Clifford. A interpretação das culturas. Rio de Janeiro, Zahar, 1978. 322 p.

10 GONÇALVES, Lúcia M. Rodrigues. Saúde Mental e trabalho social. São Paulo, Cortez, 1983. 116 p.

11 JASPERS, Karls. Psicopatologia Geral. Rio de Janeiro, Atheneu, 1973.

12 MASLOW, Abraham. Motivação e Personalidade. São Paulo, Harper e Row, 1979. 
13 MINZONI, M. Aparecida et alii. Pensando em psiquiatria preventiva. Enf. Novas Dimensões. 3 (3):141-6, jul/set. 1977.

14 ORGANIZAÇÃO MUNDIAL DE SAÚDE. Saúde da criança: riqueza do mundo. A saúde do mundo. Genebra, jan/fev. 1984.

15 ROgERS, CARL R. De Pessoa para Pessoa: $O$ problema do ser humano, uma nova tendência na psicologia. São Paulo, Pioneira, 1976. 328 P.
16 SANDSTRÖM, C. ?. A psicologia da infância e da adolescência. 7. ed. Rio de Janeiro, Zahar, 1980. 288 p.

17 TEIXEIRA, Eni M. Ribeiro. Integração da enfermagem psiquiátrica. Revista Paulista de Enfermagem, 4(4): out/nov/dez. 1984.

18 TORRES, M.B.L. Della. $O$ homem e a sociedade; uma introdução à sociologia. 6. ed. São Paulo, Nacional. 1977. $256 \mathrm{p}$.

19 UNICEF - Serviços básicos para crianças e mulheres. Brasília. UNICEF, 1984. $101 \mathrm{p}$. 